\title{
EFFECT OF TEMPERATURE AND HUMIDITY IN THE SCHIRMER TEAR TEST* ${ }^{*}$
}

\author{
BY \\ JOHN WILLIAMSON $\ddagger$ \\ Ophthalmic Institute, Glasgow Royal Infirmary \\ AND \\ MARJORIE ALLISON \\ Centre for Rheumatic Diseases, Baird Street, Glasgow
}

THE Schirmer I tear test developed and standardized by Halberg and Berens, New York City (Contactisol Inc. Lindenhurst, N.Y.) is a useful screening procedure for keratoconjunctivitis sicca in large numbers of patients suffering from various connective tissue disorders.

When all the patients attending a centre for rheumatic diseases were subjected to this test it was noted that a surprisingly high percentage of in-patients had positive Schirmer I readings (less than $15 \mathrm{~mm}$.). At the time of writing, 338 in-patients (age range 18 to 72 years, mean 56) including 250 females and 88 males, had been examined. In 65 patients ( 20 per cent.) whose ages ranged from 25 to 70 years (mean 50.5), 123 eyes had shown apparently reduced tear flow, 78 producing less than $5 \mathrm{~mm}$. of wetting. When, however, the test was repeated within the week at an ophthalmic out-patients department, all the results were negative.

The 65 patients were tested the following week in the rheumatic hospital and tear flow was again apparently reduced in 110 eyes.

\section{Investigations}

A thermographic recording and simultaneous measurements of the humidity using a whirling string hygrometer (wet and dry bulb), were made in both hospitals over a period of 20 days.

Fig. 1 (opposite) shows part of the tracing from the rheumatic hospital, where the mean temperature was $72 \cdot 3^{\circ} \mathrm{F} .\left(22 \cdot 3^{\circ} \mathrm{C}\right.$.), and the humidity $40 \cdot 5$.

Fig. 2 (opposite) shows part of the tracing from the eye hospital, where the mean temperature over the same period was $57 \cdot 4^{\circ} \mathrm{F} .\left(14 \cdot 1^{\circ} \mathrm{C}\right.$.), and the humidity 48 .

During the recording time, twelve of the patients (age range 40 to 58 years; mean 49) with apparently reduced tear flow were moved between the two hospitals on three occasions. Six recordings of the Schirmer I tear test were made available in each eye, three from the rheumatic centre and three from the ophthalmic hospital. The Table (opposite) shows the results.

All had rose bengal 1 per cent. instilled into the conjunctival sac and were examined by a modern Zeiss slit-lamp. None of the patients had keratoconjunctivitis sicca.

Clearly the Schirmer tear test was consistent in each hospital, but it was always consistently lower in the higher temperature and lower humidity of the rheumatic wards.

An interesting feature of this experiment was that the tear flow was not noticeably reduced until after 12 hours' in-patient stay in the rheumatic wards.

* Received for publication March 7, 1966.

$\dagger$ Address for reprints:

‡ Present address: Department of Ophthalmology, Southern General Hospital, Glasgow. 


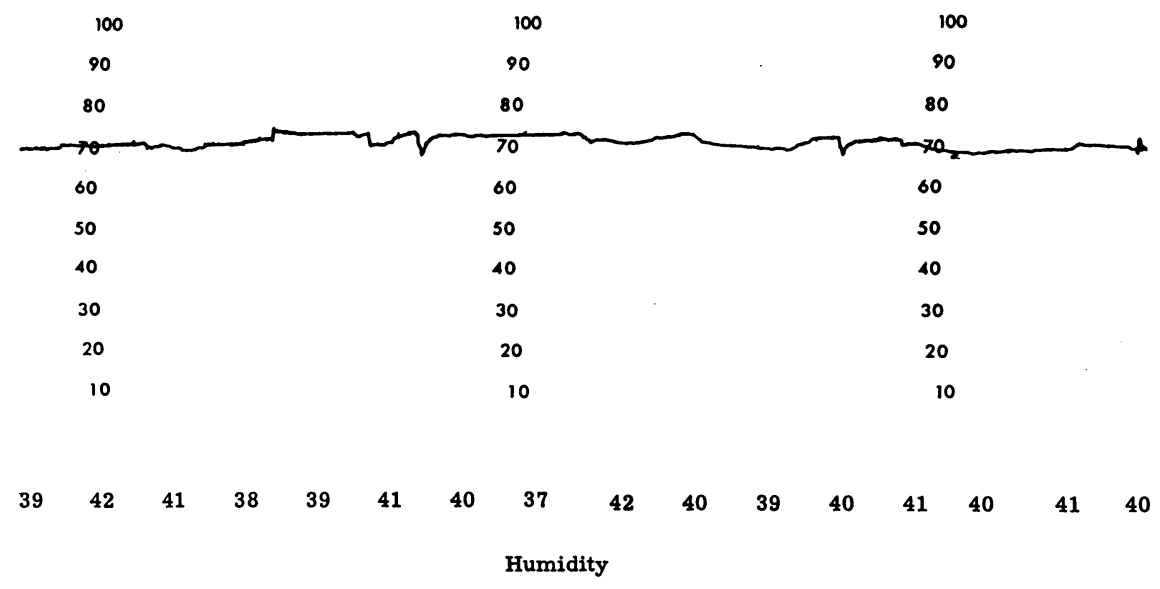

Fig. 1.-Thermograph recording in a rheumatic hospital.

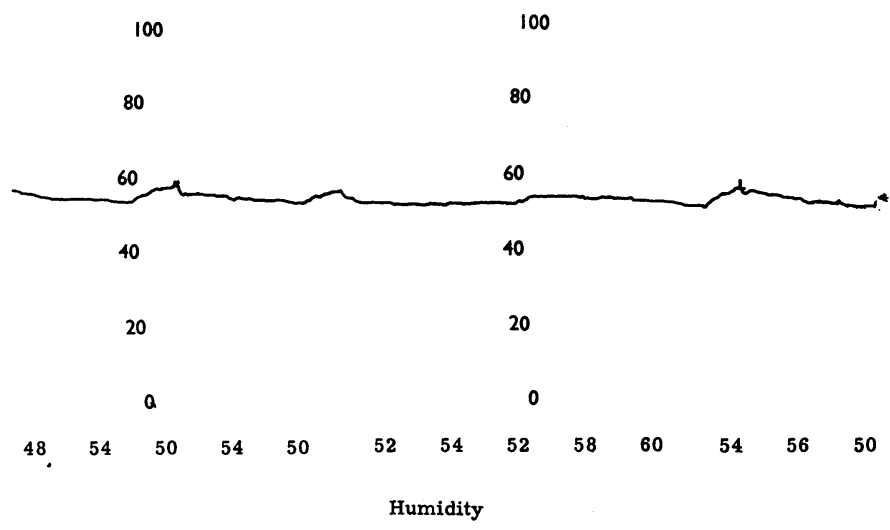

Fig. 2.-Thermograph recording in an ophthalmic out-patients department.

TABLE

\begin{tabular}{c|c|c|c}
\hline \multirow{2}{*}{ Case No. } & \multirow{2}{*}{ Sex } & \multicolumn{2}{|c}{ Three Recordings (average of two eyes) } \\
\cline { 3 - 4 } & & At Rheumatic Hospital & At Ophthalmic Hospital \\
\hline 1 & F & $11,12,11$ & $15,18,18$ \\
2 & $\mathrm{~F}$ & $8,7,7$ & $20,20,19$ \\
3 & $\mathrm{M}$ & $4,8,7$ & $16,18,17$ \\
4 & $\mathrm{~F}$ & $3,7,5$ & $20,18,20$ \\
5 & $\mathrm{~F}$ & $8,12,11$ & $20,20,20$ \\
6 & $\mathrm{M}$ & $12,11,12$ & 22, C.W., C.W. \\
7 & $\mathrm{M}$ & $14,15,10$ & $18,18,20$ \\
8 & $\mathrm{M}$ & $15,11,14$ & $19,20,20$ \\
9 & $\mathrm{M}$ & $14,12,13$ & 22, C.W., C.W. \\
10 & $\mathrm{~F}$ & $12,9,8$ & $20,18,16$ \\
11 & $\mathrm{M}$ & $7,6,4$ & $20,16,20$ \\
12 & $\mathrm{~F}$ & $3,2,0$ & 20, C.W., 20 \\
\hline
\end{tabular}

(C.W. = completely wet $)$ 
The twelve patients were then followed up during the next 20 days, the Schirmer I test being repeated every second night. During this time, there was no tendency for the patients to compensate by increased production of tears, i.e. the results remained consistently low. Within 3 days of hospitalization, ten of the patients complained that their eyes felt hot and dry towards early afternoon, and within the week so did the rest.

\section{Discussion}

65 out of 338 patients ( 20 per cent.) admitted to a rheumatic centre showed apparently reduced tear flow (less than $15 \mathrm{~mm}$.) after 12 hours' hospitalization, as judged by the Schirmer I tear test. All were measured within the week at an ophthalmic out-patients department and were found to have normal tear flow. The findings appear to be related to the differences in temperature and humidity in the two hospitals. Twelve of the patients were repeatedly measured in both departments and the results were consistent. Over a period of 20 days, no tendency to compensate for the high temperature and low humidity in the rheumatic wards was observed. Symptoms of dry eyes developed in 3 days in ten of the patients and in all within the week.

A number of interpretations may be put on this observation. The apparently reduced tear flow may have been the result of increased evaporation in the warm, dry rheumatic wards. If this were correct, however, then the apparent diminution in tear flow would not have taken 12 hours to develop from the time of admission. Further, it may be asked why it should have affected only 20 per cent. of the patients and not all of them and why this effect remained consistent for this selected group of in-patients.

If the tear flow was actually increased for emotional or other reasons during the first 12 hours of admission, this might account for the apparently normal Schirmer I tear tests.

On the other hand, there may be a true lack of response to dry heat in some individuals, i.e. these findings may be physiological. The only way to prove this would be to admit a group of patients, suffering neither from connective tissue disorders nor from any disease believed to have an immunological basis, to the rheumatic centre for several days. Clearly this is impractical.

Finally, the lack of response to temperature and/or humidity may occur only or more readily in patients who are likely to develop keratoconjunctivitis sicca at a later date. It will be extremely interesting, therefore, to follow these patients over the next decade.

\section{Summary}

A temperature of around $72^{\circ} \mathrm{F} .\left(22^{\circ} \mathrm{C}\right.$.) and/or humidity of around 40.5 results in a reduced Schirmer I tear test after 12 hours of in-patient stay in about 20 per cent. of patients suffering from connective tissue disorders. No tendency to compensate for this reduction was noted in twelve patients over 20 days despite the fact that they developed symptoms of dry eyes. The possible significance of this observation is discussed. 